\title{
Studi Faktor Pengaruh Iklim Keselamatan Kerja dalam Proyek Konstruksi
}

\author{
Diah Listyaningsih ${ }^{*}$, Feri Harianto ${ }^{1}$, Rahma Saraswati ${ }^{1}$ \\ ${ }^{1}$ Program Studi Teknik Sipil, Fakultas Teknik Sipil dan Perencanaan, Institut Teknologi Adhi Tama Surabaya \\ Email: *diahlistya@itats.ac.id
}

\begin{abstract}
Accidents in construction project often occur, especially in the construction world. Safety climate plays an important role in the success of a project. By using a literature study, this article aims to find out what factors affect climate. This study uses 14 journals and consists of 17 articles that focus on the climate of work safety. The results showed that 13 factors were generated which were categorized into physical and non-physical. Physical factors that influence are physical fatigues, low adaptability, motor skills, leadership management, systematic work preparation, safety behaviour and injuries. Meanwhile, non-physical consisted of 5 factors: organizational climate, emotional stress, psychological conflict, personality, intelligence and motivation, psychosocial conditions. For further research, factor analysis will be carried out regarding the factors that have been found by surveying construction workers in Indonesia. The association of these factors with the safety climate can also be found.
\end{abstract}

Keywords: Construction, Occupational Health and Safety, Safety climate

\begin{abstract}
Abstrak
Kecelakaan kerja sering terjadi terutama di dunia konstruksi. Iklim Keselamatan Kerja berperan pernting terhadap keberhasilah suatu proyek. Dengan menggunakan studi literatur, artikel ini bertujuan untuk mencari faktor-faktor yang berpengaruh terhadap iklim Dalam penelitian ini digunakan metode studi literatur. Penelitian ini menggunakan 14 jurnal dan terdiri dari 17 artikel yang berfokus pada Iklim Keselamatan Kerja. Hasilnya didapatkan 13 faktor yang dihasilkan yang dikategorikan menjadi fisik dan non fisik. Faktor fisik yang mempengaruhi adalah korban, rendahnya kemampuan beradaptasi, keterampilan motoris, manajemen kepemimpinan, persiapan Kerja yang sistematis, perilaku keselamatan dan cedera. Sedangkan untuk non fisik terdiri dari 5 faktor: iklim organisasi, tekanan emosi, konflik kejiwaan, kepribadian, intelegensi dan motivasi, kondisi psikososial. Untuk penelitian selanjutnya akan dilakukan analisis faktor mengenai faktorfaktor yang sudah ditemukan dengan melakukan survei pekerja Konstruksi di Indonesia. Hubungan mengenai faktor tersebut dengan iklim keselamatan juga dapat ditemukan.
\end{abstract}

Keywords: Iklim Keselamatan Kerja, K3, Konstruksi

\section{Pendahuluan}

Sektor Konstruksi mempunyai risiko tinggi dalam kecelakanan pada tahap pelaksanaannya. Beberapa perusahaan yang tidak menerapkan sistem Kesehatan dan Keselamatan Kerja (K3) disebabkan karena sebagian besar pelaku konstruksi masih berfikir bahwa K3 akan meningkatkan biaya proyek konstruksi. Iklim Keselamatan Kerja mempengaruhi pengetahuan, motivasi, kepatuhan dan partisipasi individu [1]. Selain itu, iklim keselamatan kerja dan kepribadian big five juga berpengaruh terhadap perilaku keselamatan karyawan [2].

Kecelakaan kerja memiliki korban jiwa yang signifikan dan berdampak negatif terhadap beberapa sub bidang dalam Konstruksi, seperti produktivitas perusahaan, keuangan, dan lain-lain. Studi yang bertujuan untuk mengeksplorasi pengaruh interaksi manajemen keselamatan dan penyebab iklim keselamatan terhadap kinerja Keselamatan dilakukan dengan menguji model yang diusulkan menggunakan kuadrat terkecil parsial [3]. Temuan menunjukkan bahwa sistem manajemen keselamatan memiliki efek positif pada kinerja keselamatan. Selanjutnya, interaksi insentif keselamatan, keterlibatan subkontraktor, dan akuntabilitas keselamatan dengan sistem manajemen keselamatan memiliki efek positif yang signifikan terhadap kinerja keselamatan. Oleh karena itu, agar berhasil menerapkan sistem 
manajemen keselamatan dan meningkatkan kinerja keselamatan, perusahaan konstruksi perlu memberikan insentif keselamatan dan menghubungkannya ke semua aspek sistem manajemen keselamatan mereka, melibatkan subkontraktor dalam pertemuan dan pelatihan keselamatan, serta memberikan tanggung jawab dan wewenang kepada siapa pun yang terlibat. dalam pelaksanaan proyek konstruksi.

Iklim Keselamatan berpengaruh terhadap perilaku risiko dimana ketika tekanan produksi rendah, maka pengaruh komitmen manajemen terhadap keselamatan perilaku berisiko rendah begitu juga sebaliknya [5]. Temuan ini menyoroti pentingnya komitmen manajerial yang merupakan dimensi dalam iklim Keselamatan dalam konteks di mana karyawan mengalami ketegangan antara tenggat waktu produksi dan prosedur Keselamatan.

Iklim Keselamatan kerja sendiri dipengaruhi oleh beberapa faktor, diantaranya adalah tekanan emosi, kelelahan fisik, konflik kejiwaan, kurangnya kemampuan beradaptasi terhadap lingkungan, kepribadian, intelegensi dan motivasi serta kurangnya keterampilan sensoris dan motoris [6]. Dengan mengeksplore sebuah model, ditemukan bahwa iklim Keselamatan Kerja dipengaruhi oleh keamanan kepemimpinan dan iklim Keselamatan Kerja sendiri mempengaruhi motivasi Keselamatan Kerja [9]. Iklim Keselamatan Kerja dan pengalaman personal berpengaruh juga terhadap kepatuhan pada peraturan Keselamatan [10]. Dalam penelitian lain disebutkan bahwa peranan seorang pemimpin seperti supervisor atau mandor sangat berpengaruh terhadap iklim Keselamatan Kerja [11]. Dengan melakukan survei kepada serratus empat belas bekerja dari sembilan kontraktor yang berbeda, menunjukkan tingkat iklim Keselamatan Kerja tingkat grup yang unik. Hasilnya menunjukkan behwa personil baik supervisor maupun mandor memainkan peranan penting dalam membentuk kinerja Keselamatan pada kelompok Kerja subkontrak. Sejalan dengan penelitian Lingard, pengaruh pemimpin melalui gaya kepemimpinannya memiliki hubungan signifikan dengan partisipasi [12]. Pemimpin dapat mendorong partisipasi Keselamatan dengan menggunakan taktik mempengaruhi, berargumen secara rasional, terlibat dalam pengambilan keputusan dan membangkitkan rasa antusiasme untuk Keselamatan.

Dalam melakukan pekerjaan Konstruksi tentunya harus ada persiapan yang sangat matang. Dalam siklus hidup proyek disebutkan bahwa siklus hidup proyek mempunyai empat tahap, yaitu defining, planning, excecuting dan closing [13]. Setiap tahapnya harus dipersiapkan dengan baik, karena akan selalu ada pengontrolan atau evaluasi. Rapat persiapan Kerja bisa dilakukan secara berkala, ataupun pada waktu tertentu saat diskusi dan pertemuan dibutuhkan. Misalnya saja pada morning safety talk, biasanya dilakukan di pagi hari sebelum memulai pekerjaan. Begitu juga dengan rapat persiapan pekerjaan yang lain ataupun rapat kemajuan pekerjaan. Rapat persiapan Kerja tersebut diharapkan memiliki efek positif pada nilai Keselamatan di tempat Kerja. Akan tetapi, berlawanan dengan ekspektasi, penelitian yang dilakukan pada enam lokasi Konstruksi besar menghasilkan adanya penurunan Keselamatan Kerja [14]. Seringnya pertemuan Kerja memang sering dapat mendiskusikan beberapa masalah terkait iklim Keselamatan, akan tetapi tergantung bagaimana pertemuan ini dilakukan dan prioritas apa yang disampaikan. Pertemuan tidak selalu membahas hal atau masalah secara efektif, tetapi terkadang juga sering terjadi pembahasan lain di luar permasalahan inti. Hal tersebutlah yang menyebabkan pertemuan tidak memberi pengaruh positif terhadap Keselamatan Kerja.

Studi lain membandingkan dan mengukur iklim keselamatan di fasilitas manufaktur (kinerja keselamatan tinggi vs. kinerja keselamatan rendah) untuk mengidentifikasi area yang paling berdampak untuk mengurangi atau mencegah cedera di tempat kerja. Untuk mencapai tujuan studi, digunakan Kuesioner Iklim Keselamatan Nordik (NOSACQ-50) yang terdiri dari 50 item di tujuh dimensi. Sebanyak 116 karyawan operasional di pabrik kertas laminasi di Amerika Serikat dan memiliki struktur operasi yang sama menyelesaikan survei. Hasil perbandingan menunjukkan bahwa terdapat perbedaan yang besar pada skor total. Situs berkinerja tinggi memiliki skor NOSACQ-50 yang jauh lebih tinggi daripada situs berkinerja buruk di semua dimensi yaitu pada tiga area fokus: komitmen, keterlibatan, dan akuntabilitas [16]. Konseptual model untuk iklim Keselamatan psikologi sendiri sudah dikembangkan dengan melihat perspektif struktural, perseptual, interaktif, dan budaya [17]. Maka dari itu perlu dilakukan penelitian yang berhubungan dengan perilaku keselamatan kerja pada proyek konstruksi. 


\section{Metode}

Metode yang digunakan dalam penelitian ini adalah studi literatur dengan menggunakan 14 jurnal yang berfokus pada Iklim Keselamatan Kerja, diantaranya International Journal of Project Management, Risk Analysis, Accident Analysis and Prevention, Industrial and Systems Engineering Review, Journal of applied social psychology, Individual Behaviour, Jurnal Psikologi, Jurnal Psikologi Teori dan Terapan, Jurnal Manajemen Teknologi, Jurnal Psikologi Mandiri, Safety Science, Children and Youth Services Review, dan Insight

Ada tiga tahap yang akan digunakan dalam pemilihan jurnal: 1) penggunaan kata kunci, yaitu iklim Keselamatan Kerja dan safety climate; 2) memilih artikel yang berhubungan dengan judul yang dibahas; 3) studi literatur dan mencari faktor yang berpengaruh. Dalam pencarian jurnal, beberapa database yang digunakan antara lain: Google Scholar, Science Direct dan researchgate. Tahapan dalam penulisan ini digambarkan pada gambar 1 .

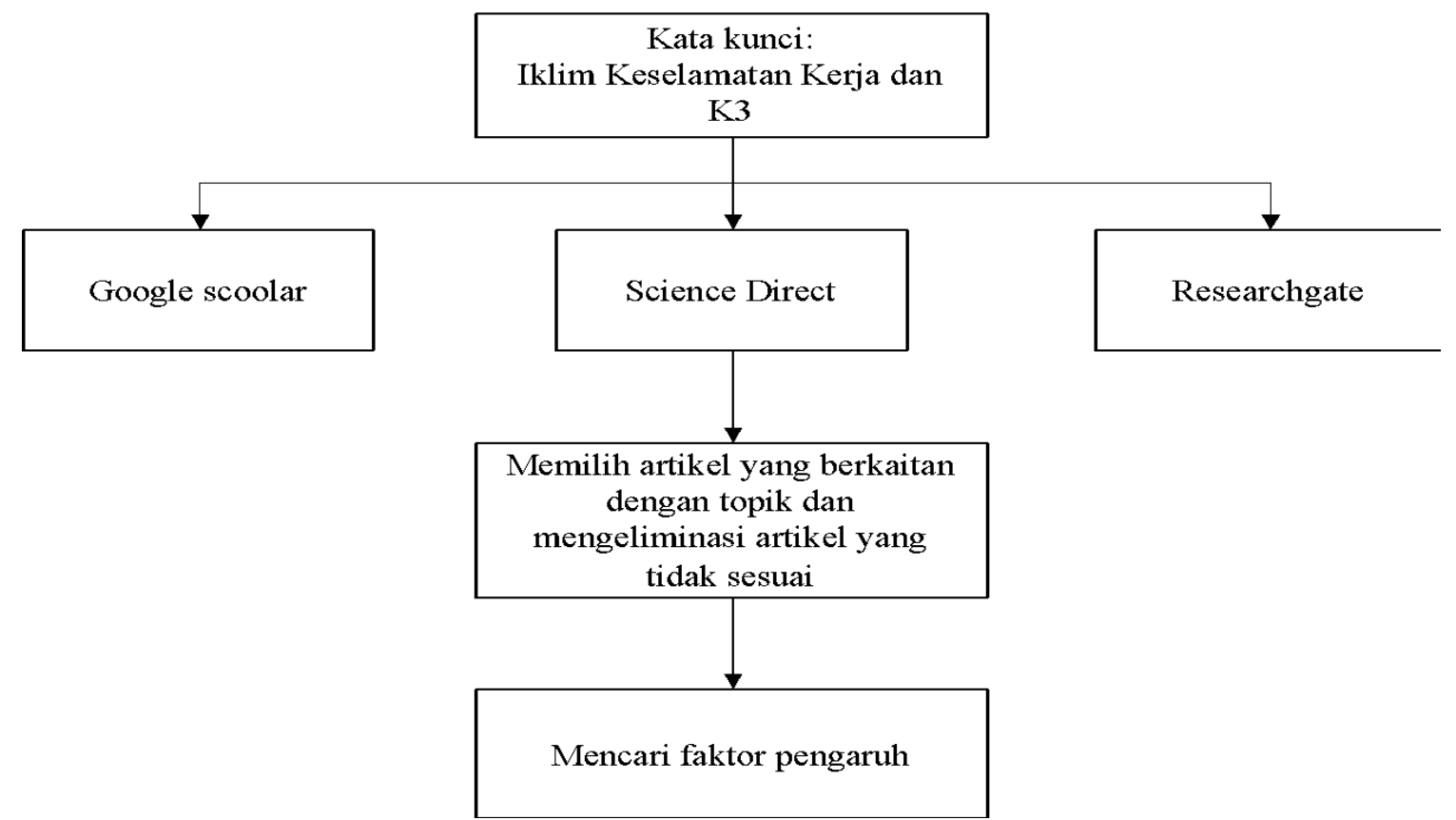

Gambar 1. Proses literatur review

Dari beberapa jurnal tersebut akan dilakukan pemetaan beberapa artikel. Dengan beberapa jurnal dicari kata kunci yang berhubungan dengan Iklim Keselamatan Kerja dan K3. Tabel 1 menampilkan hasil pencarian artikel dalam beberapa jurnal.

\section{Hasil dan Pembahasan}

Dari beberapa artikel yang terpilih, ada beberapa faktor yang berhubungan dengan iklim Keselamatan Kerja seperti ditunjukkan pada tabel 2.

Tabel 1. Hasil pencarian artikel

\begin{tabular}{lc}
\hline \multicolumn{1}{c}{ Nama Jurnal } & Jumlah Artikel \\
\hline Construction Management and Economics & 2 \\
International Journal of Project Management & 1 \\
Risk Analysis & 1 \\
Accident Analysis and Prevention & 2 \\
Industrial and Systems Engineering Review & 1 \\
Journal of applied social psychology & 1 \\
Individual Behaviour & 1 \\
Jurnal Psikologi & 1 \\
\hline
\end{tabular}




\begin{tabular}{lc}
\hline \multicolumn{1}{c}{ Nama Jurnal } & Jumlah Artikel \\
\hline Jurnal Psikologi Teori dan Terapan & 1 \\
Jurnal Manajemen Teknologi & 1 \\
Jurnal Psikologi Mandiri & 1 \\
Safety Science & 2 \\
Children and Youth Services Review & 1 \\
Insight & 1 \\
\hline
\end{tabular}

Tabel 2. Faktor faktor yang mempengaruhi iklim Keselamatan Kerja

\begin{tabular}{clll}
\hline No. & Faktor & Penulis & Kategori \\
\hline 1 & Iklim organisasi & Neal (2000) & Non Fisik \\
2 & Tekanan emosi & Widyastuti dan Aini (2014) & Non fisik \\
3 & Kelelahan fisik & Widyastuti dan Aini (2014) & Fisik \\
4 & Konflik kejiwaan & Widyastuti dan Aini (2014) & Non fisik \\
5 & Kurangnya kemampuan beradaptasi terhadap lingkungan & Widyastuti dan Aini (2014) & Fisik \\
6 & Kepribadian & Widyastuti dan Aini (2014) & Non fisik \\
7 & Intelegensi dan motivasi & Widyastuti dan Aini (2014); & Non fisik \\
& & Kuda dkk (2016) & Fisik \\
9 & Keamanan kepemimpinan & Widyastuti dan Aini (2014) & Fisik \\
& & Huda dkk (2016), Lingard dkk. & (2010); Clarke dan Ward \\
10 & Persiapan kerja yang sistematis & (2006); Petitta (2017) & Fisik \\
11 & Perilaku keselamatan & Pousette dan Torner (2016) & Fisik \\
12 & Kondisi psikososial & Pousette dan Torner (2013) & Non fisik \\
13 & Injury & Pousette dan Torner (2013) & Fisik \\
& & Beus dkk. (2010) & \\
\hline
\end{tabular}

\subsection{Faktor Fisik}

Efek moderat lintas level dari individu ke organisasi dari iklim keselamatan dibatasi oleh dimensi budaya keselamatan tertentu, sehingga iklim keselamatan memoderasi hubungan kepatuhan penegakan pengawas hanya di bawah dimensi budaya. Selain itu, dimensi budaya otokrasi dan birokrasi melemahkan hubungan antara penegakan pengawas dan kepatuhan. Hubungan yang kompleks antara budaya keselamatan organisasi dan iklim keselamatan, menunjukkan bahwa organisasi dengan budaya keselamatan tertentu mungkin lebih mungkin untuk mengembangkan iklim keselamatan yang lebih (atau kurang) positif. Selain itu, kepatuhan keselamatan karyawan adalah fungsi dari kepemimpinan keselamatan pengawas, serta dimensi iklim keselamatan dan budaya keselamatan yang lazim dalam organisasi [4].

\subsection{Faktor Non Fisik}

Pengaruh iklim organisasi secara umum pada kinerja keselamatan dimediasi oleh iklim keselamatan, sedangkan iklim keselamatan berpengaruh pada Keselamatan kinerja sebagian dimediasi oleh pengetahuan dan motivasi Keselamatan [1]. Iklim organisasi berhubungan dengan tingkat kepuasan pekerja sehingga mempengaruhi Kerja pekerja dan pekerja untuk stay di dalam suatu perusahaan [18].

Hubungan sebab dan akibat antara kondisi psikososial, iklim keselamatan, dan perilaku Keselamatan diteliti melalui pengumpulan kuesioner dari 289 karyawan di 43 unit pada empat kesempatan selama 21 bulan pembangunan terowongan jalan. Data dianalisis menggunakan dua pendekatan untuk perubahan pemodelan, yaitu model variabel laten autoregresif dan model kurva pertumbuhan multi-level. Hasil penelitian menunjukkan bahwa persepsi individu tentang iklim keselamatan memberikan efek kausal pada perilaku keselamatan individu, tetapi terdapat juga hubungan terbalik, di mana perilaku keselamatan mempengaruhi iklim keselamatan. Selain itu, persepsi rata-rata 
unit kerja tentang iklim keselamatan memprediksi pertumbuhan perilaku keselamatan individu tetapi pengaruh ini dimediasi oleh persepsi individu tentang iklim keselamatan. Hasil tersebut juga menunjukkan bahwa kondisi psikososial yang mendukung dalam suatu organisasi mempengaruhi persepsi keselamatan individu tetapi tidak berdampak pada perilaku Keselamatan [15].

Penelitian mengenai cedera dalam bekerja diteliti dan dihasilkan hubungan kuat dengan iklim Keselamatan [7]. Cedera dapat terjadi karena kurangnya kesadaran akan perilaku K3 maupun karena kelelahan psikologi dan fisik. Semakin positif persepsi karyawan terhadap iklim Keselamatan, maka semakin tinggi tingkat kepatuhan karyawan terhadap peraturan Keselamatan Kerja yang ada [8].

\section{Kesimpulan}

Hasil dari studi adalah terdapat 13 faktor yang ditemukan mempengaruhi iklim Keselamatan Kerja, baik yang berpengaruh positif maupun negatif, dan berpengaruh besar maupun kecil. Kemudian faktor-faktor tersebut dikategorikan lagi ke dalam kategori fisik dan non fisik. Sehingga, dapat diketahui bahwa faktor fisik yang mempengaruhi adalah kelelahan, rendahnya kemampuan beradaptasi, keterampilan sensoris motoris, keamanan kepemimpinan, persiapan Kerja yang sistematis, perilaku Keselamatan dan injury. Sedangkan, untuk non fisik terdiri dari 5 faktor: iklim organisasi, tekanan emosi, konflik kejiwaan, kepribadian, intelegensi dan motivasi, kondisi psikososial.

Untuk penelitian selanjutnya akan dilakukan analisis faktor mengenai faktor-faktor yang sudah ditemukan dengan melakukan survei ke pekerja Konstruksi di Indonesia. Hubungan mengenai faktor tersebut dengan iklim Keselamatan juga dapat ditemukan.

\section{Referensi}

[1] A. Neal, M. A. Gri, and P. M. Hart, "Neal 2000 SafetySci org climate impact on behav!," J. Individ. Behav., vol. 34, no. 1, pp. 99-109, 2000.

[2] P. Prabarini and F. Suhariadi, "Iklim Keselamatan Kerja dan Big Five Personality Sebagai Prediktor Perilaku Keselamatan Karyawan,” J. Psikol. Teor. dan Terap., vol. 9, no. 1, p. 1, 2018, doi: 10.26740/jptt.v9n1.p1-16.

[3] N. K. Kim, N. F. A. Rahim, M. Iranmanesh, and B. Foroughi, "The role of the safety climate in the successful implementation of safety management systems," Saf. Sci., vol. 118, no. September 2018, pp. 48-56, 2019, doi: 10.1016/j.ssci.2019.05.008.

[4] L. Petitta, T. M. Probst, C. Barbaranelli, and V. Ghezzi, "Disentangling the roles of safety climate and safety culture: Multi-level effects on the relationship between supervisor enforcement and safety compliance," Accid. Anal. Prev., vol. 99, pp. 77-89, 2017, doi: 10.1016/j.aap.2016.11.012.

[5] J. Bosak, W. J. Coetsee, and S. J. Cullinane, "Safety climate dimensions as predictors for risk behavior," Accid. Anal. Prev., vol. 55, pp. 256-264, 2013, doi: 10.1016/j.aap.2013.02.022.

[6] Widyastuti and Aini, "Hubungan antara Iklim Keselamatan Kerja terhadap perilaku berbahaya pada karyawan HUBUNGAN Produksi PT. Perkebunan Nusantara XI (Persero) PG. Djatirto," Insight, vol. 10, no. 1, pp. 87-101, 2014.

[7] J. M. Beus, S. C. Payne, M. E. Bergman, and W. Arthur, "Safety climate and injuries: An examination of theoretical and empirical relationships," J. Appl. Psychol., vol. 95, no. 4, pp. 713727, 2010, doi: 10.1037/a0019164.

[8] R. E. Sari, "Kepatuhan Peraturan Keselamatan Kerja Sebagai Mediator Pengaruh Iklim Keselamatan Kerja Terhadap Kecenderungan Mengalami Kecelakaan Kerja," J. Psikol. Mandiri, pp. 81-90, 2014.

[9] U. F. Huda, A. Sukmawati, and I. M. Sumertajaya, "Model Perilaku Keselamatan Kerja Karyawan pada Industri Berisiko Tinggi," J. Manaj. Teknol., vol. 15, no. 1, pp. 51-66, 2016, doi: 10.12695/jmt.2016.15.1.4.

[10] Prihatiningsih and Sugiyanto, "Pengaruh Iklim Keselamatan dan Pengalaman Personal terhadap Kepatuhan pada Peraturan Keselamatan Pekerja konstruksi," Pengaruh Iklim Keselam. dan Pengalaman Pers. terhadap Kepatuhan pada Peratur. Keselam. Pekerja Konstr., vol. 37, no. 1, pp. 82-93, 2015, doi: 10.22146/jpsi.7694. 
[11] H. C. Lingard, T. Cooke, and N. Blismas, "Safety climate in conditions of construction subcontracting: A multi-level analysis," Constr. Manag. Econ., vol. 28, no. 8, pp. 813-825, 2010, doi: 10.1080/01446190903480035.

[12] S. Clarke and K. Ward, "The role of leader influence tactics and safety climate in engaging employees' safety participation," Risk Anal., vol. 26, no. 5, pp. 1175-1185, 2006, doi: 10.1111/j.1539-6924.2006.00824.x.

[13] Includes: the standard for project management. 2017.

[14] A. Pousette and M. Törner, "Effects of systematic work preparation meetings on safety climate and psychosocial conditions in the construction industry," Constr. Manag. Econ., vol. 34, no. 6, pp. 355-365, 2016, doi: 10.1080/01446193.2016.1189584.

[15] S. L. Tholén, A. Pousette, and M. Törner, "Causal relations between psychosocial conditions, safety climate and safety behaviour - A multi-level investigation," Saf. Sci., vol. 55, pp. 62-69, 2013, doi: 10.1016/j.ssci.2012.12.013.

[16] B. Baertschi, S. D. Choi, and K. Ahn, "Safety Climate as an Indicator and Predictor of Safety Performance: A Case Study," Ind. Syst. Eng. Rev., vol. 6, no. 1, pp. 1-9, 2018, doi: 10.37266/iser.2018v6i1.pp1-9.

[17] Y. Shen, M. M. Tuuli, B. Xia, T. Y. Koh, and S. Rowlinson, "Toward a model for forming psychological safety climate in construction project management," Int. J. Proj. Manag., vol. 33, no. 1, pp. 223-235, 2015, doi: 10.1016/j.ijproman.2014.04.009.

[18] Y. Li, H. Huang, and Y. Y. Chen, "Organizational climate, job satisfaction, and turnover in voluntary child welfare workers," Child. Youth Serv. Rev., vol. 119, p. 105640, 2020, doi: 10.1016/j.childyouth.2020.105640. 